\title{
Apuntes sobre Julián del Casal
}

F $\mathrm{N}$ el año de gracia de 1881 dos grandes de Hispanoamérica salieron, unidos sin saberlo, al ancho mundo de la letra impresa. Rubén Darío tenía su "In memoriam" o hacía "sus primeros inciertos balbuceos literarios en periódicos de vida efímera como $\mathrm{El}$ Ensayo, El Termómetro y La Verdad". A la vez había en la Habana otro Ensayo, periódico de cuatro páginas y también de vida efímera, que apareció por segunda vez el día 13 de febrero de 1881 y tenía su redacción en la calle Oficios número 13. Pocos de sus colaboradores usaban la firma completa, pero testimonios de la época permiten afirmar que era su director José María Cadaval y estaba entre sus colaboradores el noble y liberal Panchito Chacón, infortunado heredero de los Condes de Casa Bayona, el poeta Pablo Hernández, Pérez Cabello, Antonio S. Cuyás y otros de nombre no localizable. La colección del pequeño e interesante periódico, que se conserva en la Biblioteca de la Sociedad Económica de la Habana, consta solamente de trece ejemplares, de los cuales faltan el primero y el onceno. $\mathrm{Y}$ en ellos se encuentran las primeras composiciones, hasta ahora desconocidas, de Julián del Casal y de la Lastra, firmadas simplemente como J. C. Aunque Geada asegura que los primeros poemas de Casal fueron publicados en La Cotorra, 1880, dirigida por Jerónimo Lozada —este periódico, según Francisco de P. Coronado, Io dirigía Carlos Noreña y no se conservan ejemplares-, hay un dato indiscutible que se refiere a las de El Ensayo como las propias y primeras tentativas poéticas de Casal:

En El Ensayo, allá por 1881, se dió a conocer Casal con sus poesías, que ya eran, por su belleza y corrección, hermosos augurios para lo porvenir. En aquel periódico escribieron Bobadilla, Noreña 
y Pablo Hernández, todos con un amor y un entusiasmo que no sentirán ya, de seguro, hoy que escriben en periódicos de importancia y miran sus nombres rodeados por el nimbo de la fama. iQué generación tan entusiasta $y$, sobre todo, tan gratuita, aquella de El Ensayo! (En El Figaro, 24 de abril 1892.)

Las composiciones son tres, de títulos por sí elocuentes, "Una lágrima", "El poeta y la sirena", dedicada a Carlos Noreña, y "Huérfano", dedicada a doña Clara Krick, "buena amiga de mi desgraciada madre", y están totalmente influidas por el aire zorrillesco, a la vez heineano y romántico, que era el clima poético de su tiempo. En la primera sigue la fórmula del alejandrino romántico; "Huérfano" y "El poeta y la sirena" están escritas en endecasílabos. Se está muy lejos aún de las innovaciones de Rubén en el alejandrino, metro que Casal rehuye con notable persistencia, pero en el que realizó sus primeros ensayos:

De fúnebres crespones las sienes adornadas, cubiertas sus mejillas, su rostro angelical, la niña se dirige, medrosa, al cementerio cercado de cipreses, de mirto funeral...

("Una lágrima")

Es un exacto alejandrino que sigue la fórmula impuesta por Zorrilla y que Benot calificaba ingenuamente de alejandrino castellano impecable. En cambio "Huérfano", en endecasílabos - metro del cual llegó Casal a adquirir perfecto dominio-, es más ligera, con sus típicas reminiscencias de Bécquer:

Entre nubes de fúlgidos colores baja a los mares el brillante sol, y despliega la noche sobre el mundo sus rayos impalpables de crespón.

La Iuna permanece oscurecida tras una bella nube de jazmín, cual si temiese con sus blancos rayos el rezo del mortal interrumpir.

E1 aura de la noche no se agita sobre las verdes hojas del ciprés, ni el insecto su lúgubre zumbido se atreve por los aires a extender. 
Aqui donde reposa la materia todo es tinieblas, corrupción no más; y do habita el espíritu incorrupto día sin noche, eterna claridad.

El mundo con sus pompas no penetra aquí del justo en la postrer mansión, que al ver su orgullo convertido en nada se aleja amedrentado de pavor.

Del cementerio entre los anchos muros almas tristes vagar, sólo se ven, y mármoles y cruces e inscripciones para cubrit el polvo del no set.

Lejos descubro de mi santa madre la tumba ornada con modesta cruz, donde duermen también las alegrías de mi tierna y perdida juventud.

Al dejar en su losa funeraria con un beso la esencia de mi ser, siento el frío del mármol por mis venas dilatatse en confusa rapidez.

Tal vez mañana, náufrago perdido por el mar insondable del dolor, no pueda alzar postrado ante esta tumba hacia los cielos mistica oración.

Tal vez el huracán fiero destroce de su sepulcro el pálido ciprés; y sólo habrá una lápida de piedra para cubrir el alma de mi ser.

Luna de nácar que tu luz admiras del lago sobre el lánguido cristal, ven en las noches del helado invierno la fosa de mi madre a iluminar.

Ave que elevas tus canoros trinos del firmamento a la región azul, ven a entonar tus lúgubres endechas de su sepulcro en la modesta cruz.

Nube que cruzas el azul del cielo matizada de nácar y arrebol, 
ven también en las tardes del estío a derramar en ella tu fulgor.

Errante peregrino: si en la noche ruegas por ella en tu tenaz sufrir, hay un alma en el mundo, otra en el cielo, que eternamente rogarán por ti.

(J. C., El Ensayo, 27 de marzo, 1881.)

Después de estas composiciones que señalan los comienzos literarios de un precursor y a la vez de un exacto poeta del Modernismo, se encuentra una seria laguna para el estudio de su evolución poética. No se encuentran más poemas ni prosas hasta 1885, aunque reiteradamente se ha afirmado que colaboró en el Album Necrológico a la Memoria de Maria de la Concepción Chacón, en 1883. Es muy probable que haya escrito para los primeros números de La Habana Elegante, pero la colección más completa de la revista que nos fué dable revisar, perteneciente al doctor Julio Hernández Miyares, comienza en el año 1885. Villoch afirma por otra parte, sin precisar la fecha, que escribió para El Castor, periódico o revista del Gremio de Zapateros, de que no hay ejemplares en nuestras bibliotecas. Una revisión de los periódicos publicados en la Habana entre 1880-1886, que se guardan en la Sociedad Económica de Amigos del País, dió también resultados negativos.

Es en 1885 -abril 19- cuando aparece el famoso "Nocturno" dedicado a la memoria de su padre. Un poco más tarde, en diciembre, publica "Desde lejos" y un interesante artículo en prosa sobre Manuel Reina, verdadero poeta de tránsito cuya preferencia destaca en Casal un atinado sentido de modernidad. De los alejandrinos románticos al "Nocturno" o a su prosa adornada pasan cuatro años creadores, y tal momento decisivo está cerrado para la valoración crítica por el silencio en que se mantuvo o por la pérdida de sus composiciones. Durante este paréntesis la "sirena" del sueño poético y las "blancas tumbas" se traspasan a la típica decoración del modernismo, enamorado del lujo:

Colocado sobre el blanco mármol de la elegante mesa de ébano, bajo un cuadro que representa, a la pálida clatidad del astro de la noche, una escena amorosa en el gtan canal de Venecia, entre dorado 
pebetero oriental y luciente jarrón de porcelana de Sèvres, lleno siempre de purpúreas rosas, moradas violetas y níveas azucenas...

(Artículo sobre Manuel Reina.)

Hubo un momento - cuando tenía los diecisiete años soñadoresen que el poeta fué romántico, nostálgico y atormentado. Luego se pierde su huella formal y se nos devuelve ya modernista, afrancesado, amante de Musset, apenas atado por una vaga sombra de romanticismo, al que vencerá lentamente. Durante esos cuatro años el desenvolvimiento de Casal es un secreto perdido, lleno de misterio como todas las grandes revoluciones literarias. En este intermedio fructuoso han aparecido los Versos libres y el Ismaelillo, de José Martí, y se ha preparado la gran revolución de la que nuestro poeta fué un heraldo indiscutible. Trabajando al par que un mexicano de prosa perfecta, estos dos criollos - Martí y Casal- hacen posible todo el verso nuevo con su amargura recóndita, su hermetismo orgulloso, sus metáforas inasibles. Porque no llegó el Modernismo en los barcos cargados de la literatura ágil de Francia, sino que vino también del brazo de aquel hombre multiforme que amaba los arroyos de las montañas, las luchas heroicas, los ángeles y el ave, la metáfora y e] lirio. Por él conoció América - nuestra América de habla española- a Whitman y a Poe, a Baudelaire y al misticismo con su entrega total. Su amigo y discípulo de México, Manuel Gutiérrez Nájera, sigue su huella y abre caminos insospechados. Se agrega al fin Casal al grupo —amigo y admirador de Nájera, aunque no de Martí-, y al fin adviene Silva para formar el cuarteto de los grandes maestros precursores, un tanto olvidados por el brillo más tardío que alcanzó Rubén Darío, más afortunado y extravertido. La vida larga hace de este último, un tanto injustamente, la meta y colofón del gran movimiento literario y olvida el mensaje de aquellos que señalaron el camino sin poder marchar hasta el final. Una revisión cuidadosa abriría nuevos ángulos al actual concepto del Modernismo, un tanto "rubendarizado". Y sería sorprendente constatar hasta qué punto es Martí el hombre de la palabra perdurable, Nájera el de la prosa ligera, Casal el de la angustia precursora.

Para ser un perfecto innovador consciente, el poeta Julián del Casal estaba sólidamente preparado. Su completa formación escolar lo había hecho un hombre culto en el sentido más lato del término. Conoció a Homero, a Anacreonte y a Teócrito, Píndaro y los Himnos 
de Orfeo, toda la letra griega de categoría maestra y la de categoría menor, minuciosamente detallada y transcrita en la Selecta ex classicis auctoribus graecis ad usum scholarum que publicaba la Compañia de Jesús. Del latín, a través de la Selecta ex classicis latinitatis tuvo también un ancho conocimiento con las acostumbradas dosis de $\mathrm{Ci}$ cerón y Horacio, aunque sus preferidos hayan sido, posiblemente, el Virgilio de las Geórgicas, Ovidio y Catulo y todos los elegíacos afines a su temperamento. Como la formación literaria de la época no era libresca, sino documentada directamente, Casal pudo obtener toda la savia viva de los modelos y adquirir su conocimiento a través de un trato eficaz y continuado. Su información sobre los autores de España no era menor porque los textos del Colegio transcribían generosamente a Manrique, al sabroso Garcilaso y a Fray Luis, aunque en los Modelos de la literatura castellana, para uso de las escuelas de Retórica del Real Colegio de Belén de la Compañia de Jesús, editados en la Habana en 1858 - texto en la época de Casal-, se mezclen libros y autores con una peculiar inocencia literaria.

Después el poeta se encargó de descubrir, con sus propios ojos asombrados, nuevos horizontes. Adviene entonces el conocimiento de la literatura francesa, para lo cual el Colegio de Belén, con su francés escogido, le había dado las primeras armas. En la historia de nuestras letras impera siempre la influencia francesa, y al seguir esta línea tomaba Casal el clásico derrotero de la cultura insular, que ya contaba con Augusto de Armas. Por otra parte, a través de las severas revistas cubanas le llegaba la filosofía angustiada y pesimista de Schopenhauer y de Hartmann, antecedentes ilustres del agonismo heideggeriano, en la cálida atmósfera de la filosofía finisecular. Tenía, además de temperamento, las armas para seguir todos los derroteros de avance, aunque el sedimento de su formación clásica y las lecturas españolas atemperaron un tanto el choque con la nueva literatura francesa, y a la vez su curiosidad creadora y su consciente actitud americana lo inclinaron hacia el respeto fructuoso a la literatura de América, que le llegaba a través del canje pródigo. Uno de los primeros poetas con quien establece contacto es Salvador Díaz Mirón, a quien pronto alcanzaría en el favor público, y al que supera prontamente. Admira a Urbina y escribe sobre él. Da a conocer a Icaza en la Habana. Mantiene correspondencia con Nájera y con todos los poetas conocidos de Hispanoamérica. Sus cartas entusiastas no se dirigen solamente a Huysmans o a Verlaine, sino 
también a Gómez Carrillo y a Darío. En medio de su febril actividad de cronista social, tiene tiempo aún para traducir e innovar. Es en sus primeros tiempos, a partir de 1886 , cuando comienza a traducir y divulga a Catulle Mendès y a Baudelaire en perfecta prosa española. Usa el eneasílabo antes que Darío y crea el terceto monorrimo. Todo esto en su primera época, mucho antes de que adviniera para él la gracia definitiva y lograra los versos perfectos que publicó en 1893, año de su muerte.

Sobre Casal no se ha dicho aún la última palabra. Apenas nos es conocido a través de unas noventa composiciones en verso, cuando en realidad su bibliografía consta de más de trescientos títulos que abarcan poemas, traducciones, ensayos, crítica. La leyenda lo cubre como un sueño y no deja penetrar en su genuina personalidad, llena de amargura, pero también de pequeñas y pueriles alegrías, de sueño y de trabajo afanoso. El gran amor de su vida no fué, como generalmente se cree, la dulce niña Juana Borrero, sino la gallarda María Cay, casada luego con un imponente general español. $Y$ se le acusa de artificioso por su japonesismo literario, porque se ignora que María Cay, hermana de un miembro del Consulado Chino en la Habana, usaba genuinos trajes de japonesa para asistir a las doradas fiestas de la Habana colonial. Para ella - "la cubana japonesa" de que nos habla Darío-, escribió los versos delatores de "Kakemono" que le han valido la más grave y pertinaz de las condenaciones que recibe su mensaje poético. A la vez se olvida su prosa, variada en estilo e intención, hasta hoy casi totalmente desconocida, se ignoran sus encantadoras traducciones y se ignora también que, a pesar de ser hombre de colonia sojuzgada, tuvo un profundo sentido de libertad e independencia respecto a las letras hispanoamericanas. Pocos poetas pueden ufanarse, como él, de haber avizorado la misión de nuestra gran revolución poética.

Pero aún está cubierto de leyenda, visto a través de los ojos asombrados de sus contemporáneos, ignorada su obra total. Mientras no se publique su letra dispersa, la historia del Modernismo permanecerá incompleta. Tan sólo cuando se haya buceado eficazmente en su trabajo - $\mathrm{y}$ en la vida poética de otro gran olvidado, José Martí- se podrá terminar el que es aún el menos conocido -y paradójicamente el más conocido - de los movimientos literarios de América, el comentado y maravilloso Modernismo.

Esperanza Figueroa 
